\title{
Report criticized federal drug-control policies
}

$\mathrm{A}$

report synthesizing data from three studies involving a total of 3800 people who used illicit drugs in Vancouver, British Columbia, indicates two things, according to researchers: municipally managed drug-control measures are working and federal drug-control policies opposing them are deeply flawed.

The Drug Situation in Vancouver report, released June 24 and prepared by the Urban Health Research Initiative of the British Columbia Centre for Excellence in HIV/AIDS, presents research findings dating back to 1996 indicating that Vancouver's harmreduction strategy has reduced illicit drug use and new HIV and hepatitis $\mathrm{C}$ infections, while increasing the use of health services by this population. Most dramatically, after needle exchange services were incorporated into local primary health care services, syringe sharing plummeted from $39.6 \%$ in 1996 to only $1.7 \%$ in 2011.

"We were all surprised to see syringe sharing plummet to these lows," said Urban Health's codirector and study coauthor Dr. Thomas Kerr. He noted that an increasing number of people who use illicit drugs have also stopped injecting drugs. Only $1 \%$ of people using illicit injection drugs reported a period of injection cessation for six months or more in 1996; $45 \%$ of people who use illicit drugs reported a similar period of cessation in 2011.

Kerr emphasizes that injection cessation increased alongside the introduction of needle-exchange and safeinjection services opposed by Ottawa. "This data conclusively shows that Vancouver's harm reduction strategies have worked," he maintains.

The report also documented a dramatic drop in hepatitis $\mathrm{C}$, from a high of 37.1 cases per 100 person-years in 1997 , to 1.1 cases by 2011 . There was a similarly dramatic drop in HIV transmission from a high of 8.1 cases per 100 person-years in 1997 , to 0.37 cases per 100 person-years in 2011.

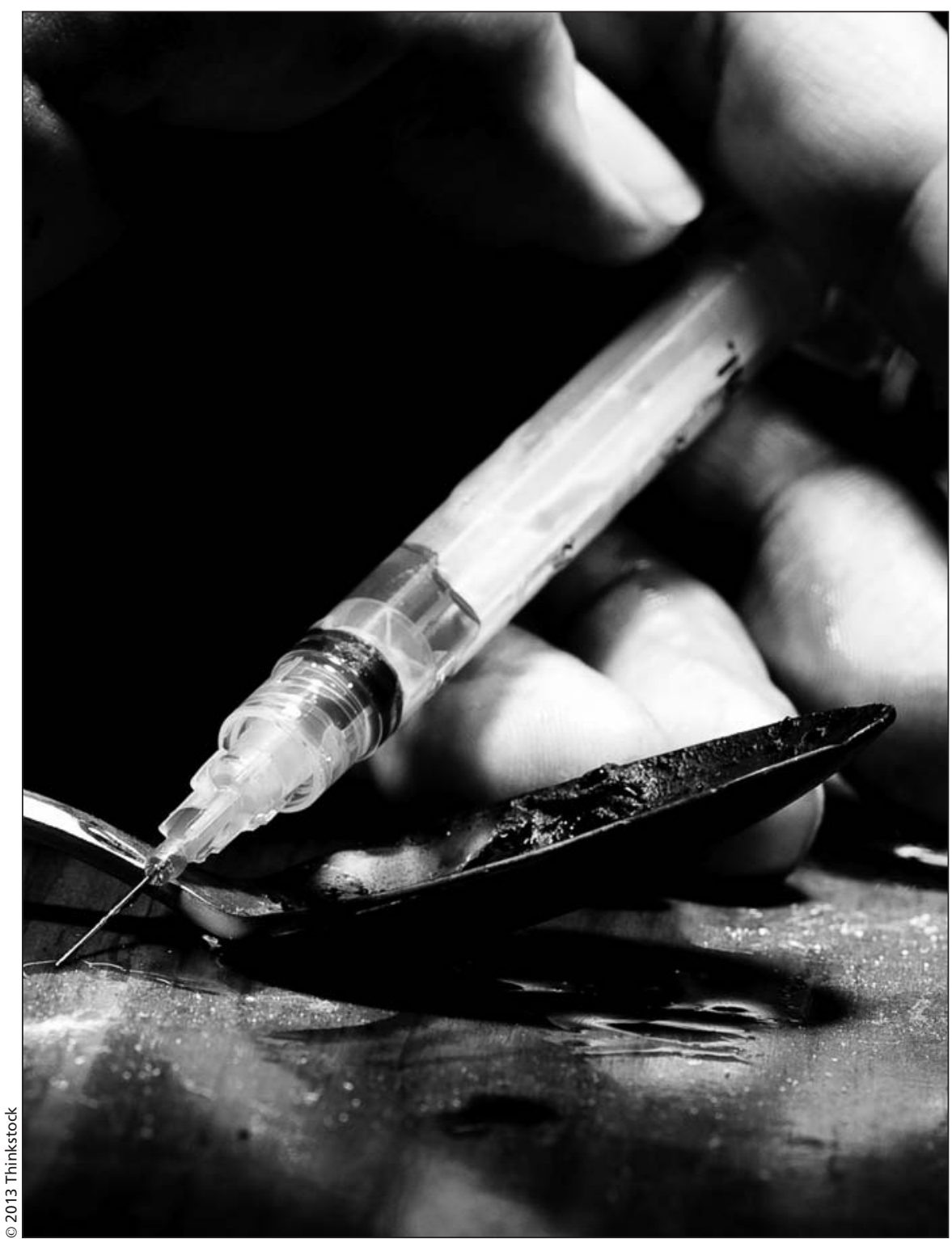

After needle-exchange services were incorporated into local primary health care services, syringe sharing plummeted from $39.6 \%$ in 1996 to only $1.7 \%$ in 2011 .

Along with the encouraging figures on needle-risk reduction and infection control, Kerr notes the data also show a steady increase in the reported use of health care treatment, accessed through methadone maintenance therapy, from $11.7 \%$ in 1996 to $53.3 \%$ in 2011 . A decreasing percentage of this population also reported difficulty accessing treatment, from a high of $19.9 \%$ in 1996 to $5 \%$ in 2011.
The report gives credit for this progress to Vancouver Coastal Health, which operates 13 hospitals, as well as providing primary and mental health care to 1 million people. In 2003, the authority adopted a harm-reduction approach to drug control by expanding access to health services for people who use illicit drugs and establishing Insite, an experimental supervised injection facility. 
In 2005, the federal Liberals adopted a similar strategy of promoting harm reduction nationally, but in 2006 the newly elected Conservative government disavowed harm reduction and launched a long-running and unsuccessful attempt to close Insite on the grounds that it promoted drug use.

This new report offers a deliberate and harsh critique of the federal government's 2007 National Anti-Drug Strategy, which does not mention support for harm-reduction strategies. The strategy does intensify support and resources for policing and incarceration of drug users - a strategy the report says puts drugusers in jails, which are known reservoirs for HIV and hepatitis C.

This approach "has put marginalized populations at higher risk of drug- related harms, [and] it appears to have had little effect on illicit drug availability and drug prices in this setting," the report concludes.

And despite federal efforts, the report indicates that the availability of illicit drugs has remained relatively high and stable over the years, and that drug prices on the street have not changed either.

Not all observers are persuaded that the data offer an explicit rebuke to Ottawa's strategy. Dr. David Juurlink, a specialist in drug-usage epidemiology at the Institute for Clinical Evaluative Sciences in Toronto, Ontario, says "it's extremely hard to make a cause-and-effect link with the federal strategy. I would caution against overinterpretation."
This opinion is echoed by the former medical director for Addiction, HIV/AIDS and Aboriginal Health with Vancouver Coastal Health (20042010). Dr. David Marsh says that although "none of these studies were designed to evaluate law enforcement or incarceration, none of them suggest there's a benefit to public health from incarceration or drug prohibitions."

The federal Department of Justice, which oversees the National Anti-Drug Strategy, and the Canadian Centre on Substance Abuse, which advises the government on drug-control policies, declined requests for interviews regarding the Vancouver study. - Paul Christopher Webster, Toronto, Ont.

CMAJ 2013. DOI:10.1503/cmaj.109-4537 